\title{
sciendo
}

\author{
BARBARA NIERADKO-IWANICKA ${ }^{1 *}$, JUSTYNA PIECHNIK², ALEKSANDRA JAREMEK², \\ ALEKSANDRA JUSZCZAK ${ }^{2}$
}

\section{Does the use of step counting devices affect the level of physical activity and body mass index of the youth studying in Lublin during COVID-19 pandemic?}

\begin{abstract}
Introduction. Due to coronavirus disease 2019 (COVID-19) many people give up exercises. International physical activity guidelines recommend 150 minutes per week of moderate- to vigorous-intensity physical activity or 75 minutes at high intensity per week. Healthy adults should take 10,000 steps per day. Wearable devices (smartwatches, step counters, physical activity monitoring applications) have the potential to promote a healthy lifestyle at the time of COVID-19 pandemic. They are accepted by the youth.

Aim. The aim of the study was to find out if using step counting devices affects the level of physical activity and body mass index (BMI) in students.

Material and methods. A total of 303 participants (227 women, 76 men) studying in Lublin, Poland of mean age 19.5 years participated in the study conducted with use of an internet questionnaire.

Results. Before the COVID-19 pandemic their mean BMI was $22.17 \mathrm{~kg} / \mathrm{m} 2$ and after 9 months of COVID-19-related restrictions it was $22.57 \mathrm{~kg} / \mathrm{m} 2$. Among the respondents $204(67.3 \%)$ did a physical activity for 50 min 3 times a week in 2019 and $99(32.7 \%)$ did not. In December 2020 there was a significant decrease in the number of students doing physical activity to $128(42.2 \%)(\mathrm{p}<0.05)$ and an increase in the number of students who did not do any physical activity to $175(57.8 \%)(\mathrm{p}<0.05)$. In 2019 as many as $110(36.3 \%)$ of the respondents used to use step counting devices and $192(63.7 \%)$ did not. In 2020 the number of students using activity tracking devices significantly decreased to $58(19.2)(\mathrm{p}<0.05)$. The number of students who did not use any step counting device in 2020 was 245 (80.8\%).

Conclusion. Due to the COVID-19 pandemic the number of students who don't do enough physical activity significantly increased. The use of step counting devices helps students in continuing physical activity despite COVID-19-related restrictions.
\end{abstract}

Keywords: step counting devices, physical activity, body mass index, students, COVID-19 pandemic.

DOI: $10.2478 /$ pjph-2021-0003

\section{INTRODUCTION}

Since 1948 the World Health Organization's definition of health has been used stating that health is not only lack of any disease but overall physical, mental and social well-being. Later there was a new definition focusing on the ability to adapt and self-manage in face of social, physical, and emotional challenges [1]. The time of coronavirus disease 2019 (COVID-19) pandemic requires from governments and citizens of all countries to implement protective measures for limiting the risk of spread of the disease via social distancing, wearing masks, hand hygiene and, if necessary, home confinement. It is a great challenge for all: students switch to e-learning, employees to remote work, elderly people stay home alone. Many people give up their routine activities, like exercises. However no confirmed coronavirus infection does not mean health, because isolation and lack of physical activity increase the risk of depressive mood disorders and metabolic diseases.

International physical activity guidelines recommend 150 minutes per week of moderate- to vigorous-intensity physical activity or 75 minutes at high intensity per week [2,3]. Such level of physical activity leads to risk reductions of at least $20 \%-30 \%$ for more than 25 chronic medical conditions and premature mortality [2]. In America the Physical Activity Guidelines for Americans, 2nd edition published in 2018 state that adults should do at least 150 minutes to 300 minutes a week of moderate-intensity, or 75 minutes to 150 minutes a week of vigorous-intensity aerobic physical activity, or an equivalent combination of moderate- and vigorous-intensity aerobic activity [4].

Healthy adults should take 10,000 steps per day [5]. Counting steps is a good motivation to maintaining some physical activity despite the policies limiting the possibility of leaving home and using sports facilities.On March 20, 2020, the Regulation of the Minister of Health issued the declaration of the SARS-CoV-2 epidemic in Poland. The provision came into force on the day of its announcement [6]. At the same time teaching in primary and secondary schools as well as at universities switched to the remote mode and continued to be that way till the end of schoolyear in June 2020. In September 2020

${ }^{1}$ Chair and Department of Hygiene, Medical University of Lublin, Poland

${ }^{2}$ Students' Scientific Association at the Chair and Department of Hygiene, Medical University of Lublin, Poland 
primary and secondary school students returned to schools. In October 2020 university students returned to the stationary mode of learning but in the middle of October due to the increasing number of infections with coronavirus in Poland, students and teachers had to switch to e-learning again. Wearable devices (smartwatches, step counters, physical activity monitoring applications) have the potential to promote a healthy lifestyle. They are accepted by the youth and elderly [7].

\section{AIM}

The aim of the study was to find out if using step counting devices affects the level of physical activity and BMI in students.

\section{MATERIAL AND METHODS}

The study was conducted in December 2020. Authors used the proprietary online questionnaire (Table 1), which was uploaded and shared on the Google online survey platform. The first year students from Lublin were invited to participate. In the city of Lublin there are several institutions offering higher education: Marie Curie-Sklodowska University (UMCS), Catholic University of Lublin (KUL), Medical University of Lublin (MUL), Lublin Polytechnic (PL), University of Enterprise and Administration in Lublin (WSPA), University of Economics and Innovation (WSEI), College of Social Sciences (WSNS), University of Life Sciences (UP). Students from each of them received invitation to participate in the study. The questionnaire consisted of 11 questions. The authors calculated respondent's BMI dividing their body mass $[\mathrm{kg}]$ by square height [m2]. Participation was voluntary and anonymous. A total of 303 students responded to the invitation and sent back the filled online questionnaire.

TABLE 1. The questions included in the survey.

\begin{tabular}{|c|c|c|}
\hline & Question & Answers to choose \\
\hline 1. & Where do you study? & $\begin{array}{l}\text { MUL, PL, UP,UMCS, KUL, } \\
\text { WSPA, WSEI, WSNS }\end{array}$ \\
\hline 2. & Gender & male; female \\
\hline 3. & How old are you? & $\begin{array}{l}\text { Open question- students filled } \\
\text { in the gap }\end{array}$ \\
\hline 4. & $\begin{array}{l}\text { What were your anthropometric } \\
\text { parameters (height and body mass) } \\
\text { in } 2019 \text { ? }\end{array}$ & $\begin{array}{l}\text { Students filled in the gap } \\
\text { provided with their height }[\mathrm{m}] \\
\text { and body mass }[\mathrm{kg}]\end{array}$ \\
\hline 5. & $\begin{array}{l}\text { What are your anthropometric } \\
\text { parameters (height and body mass) } \\
\text { now (December 2020)? }\end{array}$ & $\begin{array}{l}\text { Students filled in the gap } \\
\text { provided with their height }[\mathrm{m}] \\
\text { and body mass }[\mathrm{kg}]\end{array}$ \\
\hline & $\begin{array}{l}\text { Did you do any physical activity } \\
3 \text { times a week for minimum } \\
50 \text { min in } 2019 \text { ? }\end{array}$ & yes; no \\
\hline & $\begin{array}{l}\text { Do you do any physical activity } \\
3 \text { times a week for minimum } \\
50 \text { min in } 2020 ?\end{array}$ & yes; no \\
\hline 8. & $\begin{array}{l}\text { Did you use a pedometer, smart- } \\
\text { watch or other step counting device } \\
\text { in } 2019 \text { ? }\end{array}$ & yes; no \\
\hline 9. & $\begin{array}{l}\text { Do you use a pedometer, smart- } \\
\text { watch or other step counting device } \\
\text { now (December 2020)? }\end{array}$ & yes; no \\
\hline & $\begin{array}{l}\text { Did you take } 10,000 \text { steps a day } \\
\text { in } 2019 ?\end{array}$ & yes; no; I don’t know \\
\hline 11. & $\begin{array}{l}\text { Do you take } 10,000 \text { steps a day } \\
\text { in December } 2020 ?\end{array}$ & yes; no; I don't know \\
\hline
\end{tabular}

The collected research material was statistically processed using the IBM Statistical Product and Service Solutions (SPSS) Statistics (v. 25) statistical package (IBM, New York, NY, United States). Quantitative variables are described by means of the mean, standard deviation, as well as minimum and maximum values. The normality of the data distributions was checked using the Shapiro-Wilk test.

In order to determine the correlation between quantitative variables, the Pearson linear correlation coefficient was used, which is used to test the linear relationship between two features, provided that the distribution of the studied features is a normal distribution. The chi-square test was used to determine the relationship between the variables measured on the qualitative scale. The obtained results of the analysis were considered statistically significant at $\mathrm{p}<0.05$.

\section{RESULTS}

Out of the 303 participants 79 (26.1\%) studied at MUL, $70(23.1 \%)$ at PL, $57(18.8 \%)$ at UP, $48(15.8 \%)$ studied at UMCS, $28(9.2 \%)$ at KUL and $7(2.3 \%)$ from each of the remaining institutions (WSPA, WSEI, WSNS). Among all the respondents $76(25.1 \%)$ were men and 227 were women (74.9\%). Their mean age was 19.5 years (Tab.2.). Before the COVID-19 pandemic their mean BMI was $22.17 \mathrm{~kg} / \mathrm{m} 2$ and after 9 months of COVID-19 related restrictions in our country it was $22.57 \mathrm{~kg} / \mathrm{m} 2$. The difference among BMI values in 2019 (before the COVID-19 pandemic) and after 9 months of COVID-19 related restrictions in Poland (in December 2020) were not statistically significant. Interestingly, in 86 individuals the BMI decreased during that time.

Authors recorded that 204 respondents $(67.3 \%)$ did some physical activity for 50 min 3 times a week in 2019 and 99 (32.7\%) did not. In December 2020 there was a statistically significant decrease in the number of students, who did some physical activity for 50 min 3 times a week to $128(42.2 \%)$ $(\mathrm{p}<0.05)$ and a statistically significant increase in the number of students who did not do any physical activity to $175(57.8 \%)$ $(\mathrm{p}<0.05)$. In 2019 as many as $110(36.3 \%)$ of the respondents used to use step counting devices (50 women from MUL and 21 men from MUL; 39 men from PL) 192 (63.7\%) did not. In December 2020 the number of students using the step counting devices significantly decreased to 58 (19.2\%) (30 men from PL, 22 women from MUL and 6 men from MUL). In comparison with 2019 the difference was statistically significant $(\mathrm{p}<0.05)$. The number of students who did not use any step counting device in December 2020 was 245 (80.8\%). The difference was statically significant if compared with respective group in $2019(\mathrm{p}<0.05)$. Even though only half of the people who were physically active in 2019 used pedometers or smartwatches, they all took 10,000 steps a day (146 people; $48.3 \%$ of respondents. As many as 82 students responded that they did not take so many steps a day and 75 did not know. In December 2020 only 58 students (19.1\% of the examined group) took the 10,000 steps every day. The decrease was statistically significant $(\mathrm{p}<0.05)$ (Tab.3). The rest answered 'no' or ' I don't know'. There was a positive correlation between using a step counting device and physical activity in the students $(\mathrm{p}<0.05)$. 
TABLE 2. Characteristics of the examined group $(n=303)$.

\begin{tabular}{lccc}
\hline \hline Feature & mean \pm SD & minimum & maximum \\
\hline Age [years] & $19.5 \pm 1.1$ & 18 & 33 \\
\hline $\begin{array}{l}\text { BMI before COVID-19 } \\
\text { pandemic [kg/m2] }\end{array}$ & $\begin{array}{c}22.17 \pm 2.3 \\
\text { Men 23.1 } \\
\text { Women 20.3 }\end{array}$ & 17.5 & 28.1 \\
\hline $\begin{array}{l}\text { BMI during COVID-19 } \\
\text { pandemic [kg/m2] }\end{array}$ & $\begin{array}{c}\text { Men 23.2 } \\
\text { Women 20.4 }\end{array}$ & 17.8 & 30.0 \\
\hline
\end{tabular}

TABLE 3. Physical activity of students participating in the study and the use of step counting devices in 2019 and 2020.

\begin{tabular}{lccc}
\hline \hline $\begin{array}{l}\text { Physical activity and use of step counting } \\
\text { devices in students }\end{array}$ & $\mathbf{2 0 1 9}$ & $\mathbf{2 0 2 0}$ & p \\
\hline $\begin{array}{l}\text { Students who did some physical activity } \\
\text { for 30 min 3 times a week }\end{array}$ & 204 & 99 & $<0.05$ \\
\hline $\begin{array}{l}\text { Students who did not any physical activity } \\
\text { for 30 min 3 times a week }\end{array}$ & 128 & 175 & $<0.05$ \\
\hline Students who used step counting devices & 110 & 58 & $<0.05$ \\
\hline Students who did not use step counting devices & 192 & 245 & $<0.05$ \\
\hline Students who took 10,000 steps a day & 146 & 58 & $<0.05$ \\
\hline
\end{tabular}

\section{DISCUSSION}

Public health recommendations and government decisions during the COVID-19 pandemic in majority of countries resulted in restrictions on daily living. The effects were: social distancing, isolation, restrictions on leaving home or home confinement. These safety measures were necessary to limit the spreading of COVID-19, however the impact of these restrictions on health behaviours and lifestyles at home may be detrimental. During COVID-19 pandemic the first year students getting their education at the universities and institutions in Lublin did not significantly change their anthropometric measurements nor calculated BMI despite restriction of leaving home, lack of access to sports facilities and no physical education classes.

In the present study we showed that majority of students had their BMI within the healthy range $(18.5-24.9 \mathrm{~kg} / \mathrm{m} 2)$. We considered underweight with BMI $<18.5 \mathrm{~kg} / \mathrm{m} 2$, overweight with BMI $25-29.9 \mathrm{~kg} / \mathrm{m} 2$ and obesity at BMI equal $30 \mathrm{~kg} / \mathrm{m} 2$ or more. Waist circumference was considered normal in females if $\leq 80 \mathrm{~cm}$ and in med if $\leq 94 \mathrm{~cm}$. In the former study conducted at our department in 2014 participated 74 students. All of them were Caucasian. There were 48 women and 26 men aged 20 to 29 . Their body weight, height, waist and hip circumferences were measured and body mass index (BMI) and waist-hip ratio (WHR) were calculated. WHR was considered normal for women if $\leq 0.8$ and $\leq 1$ for men. In the group of women the mean BMI was $20.9 \mathrm{~kg} / \mathrm{m} 2 \pm 1.8$ (mean \pm SD) and in the group of men $25 \mathrm{~kg} / \mathrm{m} 2 \pm 4$. The waist circumferences of all women was $<80 \mathrm{~cm}(69 \pm 4.6 \mathrm{~cm})$. The waist circumference of 5 men was $>94 \mathrm{~cm}$, the value of average $91.2 \mathrm{~cm} \pm 13$ $\mathrm{cm}$ The WHR in all women was $<0.8$, indicating normal body proportions. Average WHR in the studied group of women was $0.7 \pm 0.04$. In the group of men, the average WHR was $0.9 \pm 0.08$ [8]. In both studies: the former and the present one majority of Polish students were properly nourished with BMIs and WHRs within the healthy ranges in $99 \%$ of participants. Interestingly, some students lost weight during the pandemic. It might be related to stress or depressive mood disorders which are often complicated by eating disorders.
The higher BMI in young men results from higher muscle mass [9]. On the other hand women care more about their looks and tend to diet more often than men. Except for short-term lockdown in March 2020, students could go out individually, without gathering in groups and do some physical activity. In social media, there was a lot of encouragement for all people to start walking, running, do Nordic-walking. When gym and swimming pools were open, students could take advantage of these facilities.

Warburton and Bred in in their metaanalysis demonstrated a dose-response relationship between physical activity and reduced risk of premature death [10]. Even during the COVID-19 pandemic some public health policies are needed to reduce the barriers to physical activity participation. The aim should be that everyone could reap the benefits of physical activity. In April 2020 there was an international online survey conducted 'Effects of COVID-19 Home Confinement on Eating Behaviour an d Physical Activity'. Authors asked questions about eating habits and physical activity before and during confinement conditions. The COVID-19 home confinement had a negative effect on all types of physical activity. The time spent in sedentary position increased from 5 to $8 \mathrm{~h}$ per day. Food consumption and meal patterns were more unhealthy than before the COVID-19 related restrictions, but alcohol binge drinking decreased significantly [11].

The mental aspect of home confinement due to COVID-19 pandemic was analysed in another publication of the same team running the international online survey. In the article published after data analysis authors noticed an increased psychosocial strain triggered by the home confinement in majority of participants [12]. Social participation and life satisfaction of participants were significantly decreased due to home confinement. There was a decrease in social activity, limited contacts with family, friends and neighbors. Participants of the study complained about lack of entertainment due to home confinement. These negative effects were associated with low life satisfaction during the COVID-19 pandemic. At the same time social contacts through digital technologies increased significantly [13].

Wearable activity trackers gain more and more popularity. Step counting devices were assessed by Tophoj et al. They tested four commercial activity trackers. The devices accurately counted steps, when individuals participating in their study walked with velocity $\geq 4 \mathrm{~km} / \mathrm{h}$. Walking at the speed $\leq 2$ $\mathrm{km} / \mathrm{h}$ was not counted accurately. Therefore authors concluded that the evaluated devices were not useful for patients walking at low speed during rehabilitation, nor for counting indoor walking, however they were accurate for young, healthy people walking outdoors at the speed of $\geq 4 \mathrm{~km} / \mathrm{h}$ [14]. The group of the first year students participating in our study seems to be the perfect group for using such devices. Walking outdoors can balance long hours spent in sedentary position while e-learning. Virtual applause, cups and medals that users receive for walking 10,000 steps motivate to increased physical activity.

Fokkema et al. after testing 10 different step counting devices came to a similar conclusion as the above mentioned team: the activity trackers performed better at an average and vigorous walking speed than at a slower walking speed[ 15]. Several other publication confirm their findings [16-18]. Tedesco et al. made a significant remark that even though the activity trackers were quite accurate in counting steps but underestimated calories so clinicians should be cautious 
in considering other parameters provided by these devices for clinical or research purposes [18].

Graf et al showed in her study that as simple intervention as encouraging patients by family doctors for reaching the target of 10,000 steps per day improves their life quality, decreases BMI, waist circumference, and blood pressure [19]. According to Kalbarczyk who collected their data in 2011-2013 in a group of 1677 participants $>55$ years of age, men are more often vigorously active than women in Poland. In general $30 \%$ of Poles were vigorously active [20]. In our present study more women than men used the wearable step counting devices and they were mainly women studying at MUL. Among men many from PL did so as well. It might result from the fact that medical, pharmacy, dentistry and nursing students are educated from the beginning of their studies about the beneficial effect of physical activity on human health. Among polytechnic students males predominate and they have sport teams, participate in sport competitions and pay attention to fitness. Our results differ from those published by Kalbarczyk et al. This may be because of different time of data acquisition and different target group of participants.

In Germany which is a neighbor country of Poland 51.7\% of men and $49.5 \%$ of women exercise for at least $1 \mathrm{~h}$ per week, but $25.4 \%$ of men and $15.5 \%$ of women reach the recommended 150 min weekly [18]. Among possible consequences associated with a sedentary lifestyle is the growing number of overweight and obese people and increasing incidences of cardio-metabolic diseases $[21,22]$.

In 2018, the results of a study conducted in Poland with the participation of a representative sample of a randomly selected 3,000 people aged 20 and above, were published [22]. The data were conducted by direct interview by trained interviewers. Three quarters $(75.2 \%)$ of adult men and $69.0 \%$ of women assessed their health as very good or good, with men clearly more often than women rating it as very good. Among the respondents as risk factors for chronic diseases and premature death, arterial hypertension was the most frequently enumerated factor- $65 \%$, and taking into account those who did not know what risk factors, favoring the disease is $38.4 \%$ of all respondents, for overweight or obesity the corresponding rates were $60.2 \%$ and $35.7 \%$, for cigarette smoking $59.4 \%$ and $35.1 \%$, high cholesterol $42.6 \%$ and $25.1 \%$ respectively. Very low awareness of the risks associated with improper diet (28.4\% and $16.8 \%$ ), low physical activity (32.1\% and $19.0 \%)$ and chronic stress $(33.3 \%$ and $19.7 \%)$. These results show an urgent need for more effective health education of Polish society [22].

The analysis conducted as part of the Global Disease Burden Study in 2017 (GBD Study 2017) indicate risk factors corresponding to the loss of the highest number of healthy years (DALY) [23]. They are for Poles: smoking, improper diet and high blood pressure. It is similar like for the general population of Central Europe, although the importance of high blood pressure is greater than diet. In 2017, only behavioral risk factors, i.e.modifiable risk factors accounted for the loss of $37.3 \%$ years lived in health in Poland. Of these the risk factors directly related to the diet accounted for $14.2 \%$, and with smoking 17.2\%. In $201833.0 \%$ of men and 31.1\% women in Poland were tobacco smokers [23]. Alcohol consumption is $12 \mathrm{~L} /$ year per capita in Poland [22]. To compare in Estonia it is the highest in Europe and reaches $15.8 \mathrm{~L}$ per capita per year [22]. In traditionally wine making countries like Italy and France they managed to reduce alcohol consumption by $50 \%$ within last few decades [21].

Overweight and obesity in Poland are responsible for the loss of $11.3 \%$ of healthy years, $11.1 \%$ among men, and women - $11.7 \%$. In Poland, we have $25.4 \%$ of overweight or obese men and $25.7 \%$ women. In all European countries, the percentage of obese people can be considered high -among men it ranges from $21 \%$ (in Slovenia) to $31 \%$ (in Malta), among women between 19\% (Denmark) and 31\% (Malta) [22].

The 2017 Eurobarometer survey results indicate that only $7 \%$ of EU residents over the age of 15 regularly (5 times a week or more) engages in sports or exercise, and 14\% take up other recreational forms of physical activity (cycling, dancing, gardening) [24]. The most active are the inhabitants of Scandinavia, the least - southern Europe. For example, 13\% Finns, 15\% Swedes, and 68\% Bulgarians, Greeks and Portuguese never take up sports activities. In comparison with other countries in Europe, the situation of Poland looks unfavorable $-5 \%$ of the population exercise regularly, and quite systematically $23 \%$; $9 \%$ regularly take other forms of activity, quite systematically $29 \%$ [22]. This result is lower than the data from 2011-2013 [20]. The $42.2 \%$ of students participating in our study who did some physical activity in 2020 is a very good result. If step counting devices can stimulate them to continue activity, we recommend its use.

\section{CONCLUSION}

Due to the COVID-19 pandemic the percentage of students who don't do enough physical activity significantly increased. However it remains higher than in the general population in Poland. The use of step counting devices helps students in continuing physical activity despite COVID-19-related restrictions.

\section{REFERENCES}

1. Nobile M. THE WHO DEFINITION OF HEALTH: A CRITICAL READING. Med Law. 2014;33(2):33-40. PMID: 27359006

2. Warburton DE, Bredin SS. Reflections on physical activity and health: What should we recommend? Can J Cardiol. 2016;32(4):495-504.

3. Jansson E, Hagströmer M, Anderssen SA. Fysisk aktivitet - nya vägar och val i rekommendationerna för vuxna. Lakartidningen. 2015;112:DP7W.

4. Piercy KL, Troiano RP, Ballard RM, et al. The physical activity guidelines for Americans. JAMA. 2018;320(19):2020-8.

5. Tudor-Locke C, Craig CL, Brown WJ, et al. How many steps/day are enough? For adults. Int J Behav Nutr Phys Act. 2011;8:79.

6. Polish Journal of Laws. Warsaw, Poland; 2020. Dz.U. 2020.491 (accessed on Dec 28th 2020).

7. Liang J, Xian D, Liu X, et al. Usability study of mainstream wearable fitness devices: Feature analysis and System Usability Scale Evaluation. JMIR Mhealth Uhealth. 2018;6(11):e11066.

8. Nieradko-Iwanicka B. Nutritional assessment of the II-year students of Medical Faculty with Dentistry Division of Medical University in Lublin - pilot study. Fam Med Prim Care Rev. 2014;16 (2):138-9.

9. Holguera RM, Turrión Nieves AI, Rodríguez Torres R, Alonso MC. Relationship of muscle mass determined by DEXA with spirometric results in healthy individuals. Arch Bronconeumol. 2017;53(7):375-80.

10. Warburton DER, Bredin SSD, Health benefits of physical activity: a systematic review of current systematic reviews. Curr Opin Cardiol. 2017;32(5):541-56.

11. Ammar A, Brach M, Trabelsi K, et al. Effects of COVID-19 home confinement on eating behaviour and physical activity: Results of the ECLBCOVID19 International Online Survey. Nutrients. 2020;12(6):1583.

12. Ammar A, Mueller P, Trabelsi K, et al. ECLB-COVID19 Consortium. Psychological consequences of COVID-19 home confinement: The ECLBCOVID19 multicenter study. PLoS One. 2020;15(11):e0240204. 
13. Ammar A, Chtourou H, Boukhris O, et al. COVID-19 home confinement negatively impacts social participation and life satisfaction: A worldwide multicenter study. Int J Environ Res Public Health. 2020;17(17):6237.

14. Tophøj KH, Petersen MG, Sæbye C, et al. Validity and reliability evaluation of four commercial activity trackers' step counting performance. Telemed J E Health. 2018;24(9):669-77.

15. Fokkema T, Kooiman TJ, Krijnen WP, et al. Reliability and validity of ten consumer activity trackers depend on walking speed. Med Sci Sports Exerc. 2017;49(4):793-800.

16. Evenson KR, Goto MM, Furberg RD. Systematic review of the validity and reliability of consumer-wearable activity trackers. Int J Behav Nutr Phys Act. 2015;12:159.

17. Svarre FR, Jensen MM, Nielsen J, Villumsen M. The validity of activity trackers is affected by walking speed: the criterion validity of Garmin Vivosmart ${ }^{\circledR}$ HR and StepWatch ${ }^{\mathrm{TM}} 3$ for measuring steps at various walking speeds under controlled conditions. Peer J. 2020;8:e9381.

18. Tedesco S, Sica M, Ancillao A, et al. Validity Evaluation of the Fitbit Charge 2 and the Garmin vivosmart $\mathrm{HR}+$ in free-living environments in an older adult cohort. JMIR Mhealth Uhealth. 2019;7(6):e13084.

19. Graf C, Schlepper S, Bauer C, et al. Feasibility and acceptance of exercise recommendations (10.000 steps a day) within routine German health check (Check-Up 35/GOÄ29)-study protocol. Pilot Feasibility Stud. 2016;2:52.

20. Kalbarczyk M, Mackiewicz-Łyziak J. Physical activity and healthcare costs: Projections for Poland in the context of an ageing population. Appl Health Econ Health Policy. 2019;17(4):523-32.

21. Ezzati M, Riboli E. Behavioral and dietary risk factors for noncommunicable diseases. N Engl J Med. 2013;369(10):954-64.

22. Wojtyniak B, Goryński P. Sytuacja zdrowotna ludności Polski i jej uwarunkowania. Warszawa; Narodowy Instytut Zdrowia Publicznego Państwowy Zakład Higieny; 2018.

23. Institute for Health Metrics and Evaluation, GBD Compare. [https:// vizhub.healthdata.org/gbd-compare/](Cited on Dec 29,2020).

\section{Corresponding author}

Prof. dr hab. Barbara Nieradko-Iwanicka

Chair and Department of Hygiene, Medical University of Lublin

11 Radziwiłłowska St., 20-080 Lublin

E-mail: barbara.nieradko-iwanicka@umlub.pl 